\title{
Validating lane drifts as a predictive measure of drug or sleepiness induced driving impairment
}

\author{
F. R. J. Vinckenbosch ${ }^{1}$ (D) - A. Vermeeren ${ }^{1} \cdot$ J. C. Verster ${ }^{2,3,4}$ • J. G. Ramaekers ${ }^{1} \cdot$ E. F. Vuurman ${ }^{1}$
}

Received: 1 August 2019 / Accepted: 3 December 2019 / Published online: 3 January 2020

(C) The Author(s) 2020

\begin{abstract}
Background Standard deviation of lateral position (SDLP) has been accepted as a reliable parameter for measuring driving impairment due to lowered vigilance caused by sleepiness or the use of sedating drugs. Recently, lane drifts were proposed as an additional outcome measure quantifying momentary lapses of attention. The purpose of this study was to validate lane drifts as outcome measure of driver impairment in a large data pool from two independent research centers.

Methods Data from 11 placebo-controlled studies that assessed the impact of alcohol, hypnotics, and sleep deprivation on actual driving performance were pooled. In total, 717 on-the-road tests performed by 315 drivers were subjected to an automated algorithm to detect occurrences of lane drifts. Lane drifts were defined as deviations $>100 \mathrm{~cm}$ from the mean $\left(\mathrm{LD}_{\mathrm{mlp}}\right)$ and from the absolute lateral position $\left(\mathrm{LD}_{\mathrm{alp}}\right)$ for $8 \mathrm{~s}$.

Results The number of $\mathrm{LD}_{\mathrm{mlp}}$ was low and did not differ between treatments and baseline, i.e., 14 vs. 3 events, respectively. $\mathrm{LD}_{\text {alp }}$ were frequent and significantly higher during treatment relative to baseline, i.e., 1646 vs. 470 events. The correlation between $\mathrm{LD}_{\mathrm{alp}}$ and SDLP in the treatment conditions was very high $\left(\mathrm{r}_{\mathrm{s}}=0.77\right)$. The frequency of the occurrence of treatment-induced lane drifts however depended on baseline SDLP of drivers, whereas treatment-induced changes in SDLP occurred independent of baseline SDLP.

Conclusion $\mathrm{LD}_{\mathrm{mlp}}$ is not useful as an outcome measure of driver impairment due to its rare occurrence, even when treatmentinduced increments in SDLP are evident. Treatment effects on $\mathrm{LD}_{\mathrm{alp}}$ and SDLP are closely related.
\end{abstract}

Keywords Drugs $\cdot$ On-the-road driving $\cdot$ SDLP $\cdot$ Lane drifts $\cdot$ Lapses of attention

\section{Introduction}

Sustained attention is a necessary requirement for the safe operation of a motor vehicle in traffic. It has been estimated that up to $15 \%$ of the traffic accidents on motor ways are associated with sleepiness (Maycock, 1996). CNS drugs such as hypnotics are known to produce sleepiness and may affect

F. R. J. Vinckenbosch

f.vinckenbosch@maastrichtuniversity.nl

1 Department of neuropsychology and psychopharmacology, Maastricht University, Maastricht, The Netherlands

2 Institute for Risk Assessment Sciences, Utrecht University, Utrecht, The Netherlands

3 Division of Pharmacology, Utrecht University, 3584CG, Utrecht, The Netherlands

4 Centre for Human Psychopharmacology, Swinburne University, Melbourne, Australia psychomotor and executive function (Jongen et al., 2018). Consequently, epidemiological studies have repeatedly demonstrated a positive association between the use of sedative medications and accident risk (Barbone et al., 1998; Movig et al., 2004; Gustavsen et al., 2008; Orriols et al., 2011).

For over 30 years, the "gold standard" for the assessment of the effects of drugs and sleepiness on driver vigilance in experimental, placebo-controlled studies has been a standardized on-the-road driving test (Ramaekers, 2017) that was developed in the Netherlands. This naturalistic test requires participants to complete a $100-\mathrm{km}$ test drive on a primary highway while accompanied by a licensed driving instructor who has access to dual controls. The participants are instructed to maintain a steady lateral position in the middle of the right traffic lane at a velocity of $95 \mathrm{~km} / \mathrm{h}$. During the drive, a camera mounted on top of the vehicle continuously monitors the vehicle's lateral position relative to the traffic lane demarcation to the left of it.

The standard deviation of lateral position (SDLP), i.e., the weaving of the car, is the main outcome measure of the 
standardized driving test. It is considered to be a quantification of lane weaving, a measure of vehicle control. It has been repeatedly demonstrated that mean SDLP increases with approximately $2.5 \mathrm{~cm}$ when driving under a blood alcohol concentration (BAC) of $0.5 \mathrm{~g} / \mathrm{L}$, relative to driving under placebo. $\mathrm{A} B A C$ of $0.5 \mathrm{~g} / \mathrm{L}$ is the legal limit for driving under the influence of alcohol in most European countries, because epidemiological studies have demonstrated that crash risk increases at concentrations exceeding this threshold (Borkenstein et al., 1974). Consequently, an increase in SDLP of $2.5 \mathrm{~cm}$ or higher represents a clinically relevant change in the on-the-road driving test when quantifying medicinal drug effects on SDLP. On-the-road driving studies have demonstrated that the use of sedative medications, such as benzodiazepines and antidepressants, and sleep deprivation can produce increments in SDLP that are equal to or greater than this clinical threshold (Jongen et al., 2018; Veldhuijzen et al., 2006; Ramaekers et al., 1998; Jongen et al., 2015). The implication is that these challenges can increase crash risk, similar to alcohol. Drug- and alcohol-induced changes in SDLP observed in the on-the-road driving tests are strongly correlated to drug- and alcohol-induced crash risk as assessed in epidemiological studies (Ramaekers, 2017). The implication is that SDLP as measured in the on-the-road driving test is not merely a measure of driver impairment but also predicts crash risk.

However, despite the agreement that the SDLP is sensitive measure for driver vigilance, it has been argued that the association between drug- and sleepiness-induced increments in SDLP and crash risk is indirect (Lococo \& Staplin, 2006; Hartman et al., 2015; Verster et al., 2014) and that other factors may play a more important role in the occurrence of an accident such as brief moments of inattention, micro-sleeps, and distraction (Verster et al., 2014; Verster et al., 2018; Verster \& Roth, 2014a). Two additional, potentially relevant, measures for predicting crash risk have been proposed, i.e., lane excursions and lane drifts, which are both derived from the same source parameter as SDLP, i.e., lateral position. Lane excursions were quickly discarded as a sensitive measure of crash because they occur infrequently and are much less sensitive than SDLP for demonstrating driver impairment (Verster \& Roth, 2014a). Lane drifts however have been proposed as a valuable measure of lapses of attention that may occur during prolonged driving (Verster et al., 2014). The authors who proposed this measure reanalyzed driving data from two double-blind, placebocontrolled on-the-road driving studies that examined the residual effects of hypnotic drugs on lateral position. The reanalysis showed that both SDLP and lapses of attention were significantly higher following administration of hypnotics as compared to placebo. A lapse of attention in this context was conceptualized by the authors as "a short period of inattention during which the driver experiences reduced alertness and does not focus on the task, or actually stops performing the task, resulting in driving impairment". It was argued that a momentary reduction or loss of attention would lead to a relatively large deviation in lateral position. Hence, a lapse of attention during the on-the-road driving test is operationalized as "a deviation from mean lateral position of more than $100 \mathrm{~cm}$ for four or more seconds" (Verster et al., 2014). Post hoc, the lapse duration criterion was increased to $8 \mathrm{~s}$ since it was found that only $4.6 \%$ of the observed deviations of $>100 \mathrm{~cm}$ had a duration of 4 to $8 \mathrm{~s}$ (Verster et al., 2014). In a later publication, an alternative operationalization was applied on the same dataset that defined a lapse "as a continuous change in lateral position of greater than $100 \mathrm{~cm}$, lasting for at least 8 seconds" (Verster et al., 2018). Both operationalizations were reported to be able to detect a significant increase in the number of lane drifts during on-the-road driving in the morning after nighttime administration of hypnotics such as zolpidem, zopiclone, and ramelteon (Verster et al., 2014; Verster et al., 2018). It was therefore concluded that lane drifts are a useful outcome measure of driving impairment during on-the-road driving that is conceptually distinct from driver impairments assessed with SDLP. So far, lane drifts as a measure of driving impairment have been piloted in two datasets from on-the-road driving studies (Verster et al., 2014; Verster et al., 2018; Mets et al., 2011) as described above. In addition, the outcome has been applied in a study on the effects of methylphenidate on the driving performance of ADHD patients where it was found that treatment significantly reduces the number of lane drifts (Verster \& Roth, 2014b). Another study into the effects of the orexin antagonist Lemborexant in healthy volunteers did not find any lane drifts at all, which is in contrast to the aforementioned findings which state that lane drifts were also apparent after placebo treatment in healthy volunteers (Verster et al., 2014). A large-scale validation of the measure's sensitivity to drug-induced impairment and how it discriminates from SDLP is still lacking. The purpose of this study was to further investigate and validate lane drifts as outcome measure of drug- and sleepiness-induced driver impairment in a large data pool from two independent research centers that included on-the-road driving data from 11 placebo-controlled studies that assessed the impact of alcohol, hypnotics, and sleep deprivation on actual driving performance.

\section{Methods}

In order to validate proposed operationalizations of lane drifts (Verster et al., 2014; Verster et al., 2018), data was pooled from 11 randomized, placebo-controlled, cross-over studies that employed the on-the-road driving test and were conducted at two independent research centers. These studies were originally designed to assess the effects of alcohol (Kuypers et al., 2006; van der Sluiszen et al., 2016), hypnotics (Jongen et al., 2018; Mets et al., 2011; Leufkens et al., 2009; Vermeeren et al., 2018; 
Vermeeren et al., 2016; Vermeeren et al., 2015; Vermeeren et al., 2014; Verster et al., 2002), and sleep deprivation (Jongen et al., 2015) and were selected for the current investigation because the administered treatments were found to significantly affect the SDLP. The pooled dataset included 315 healthy volunteers of both sexes who drove after alcohol $(N=$ $49)$, zopiclone $(N=194)$, zolpidem $(N=72)$, oxazepam $(N=$ 43), diazepam $(N=21)$ and sleep deprivation $(N=23)$ and after placebo $(N=315)$. For an overview of the studies included samples sizes per study, references, and research center, see Table 1. For studies where the effect of a substance was assessed at two successive time points, only the first measurement was included. It is noted that for two studies (Mets et al., 2011; Verster et al., 2002), the number of participants differs from the original publications because the data of 11 driving tests could not be recovered.

For every test drive, SDLP was calculated as the standard deviation relative to the mean lateral position over the entire $100-\mathrm{km}$ drive, as opposed to the average of the SDLP across 20 successive segments of $5 \mathrm{~km}$, which is traditionally employed (O'Hanlon et al., 1982; Ramaekers et al., 1992; O'Hanlon, 1984). The segmented approach corrects for drifts in the mean lane position over time that frequently occur and may lead to inflated SDLP values. Still, it was opted to calculate SDLP from the mean lateral position over the entire test drive to eliminate differences in the calculation of SDLP between the two centers. The Maastricht center traditionally uses the segmented approach for calculating SDLP, whereas the Utrecht center treats driving data over $100 \mathrm{~km}$ as a single segment (Verster \& Roth, 2011). Consequently, mean SDLP values from studies conducted in the Maastricht research center will be higher as those reported in their original publications.

In previous publications (Verster et al., 2014; Verster et al., 2018), lane drifts were evaluated and classified by visual inspection of the individual driving data. In order to control for interrater differences and to objectify the scoring procedure, an automated algorithm was created to detect occurrences of lane drifts in all individual drives. Lane drifts were defined as deviations $>100 \mathrm{~cm}$ from the mean $\left(\mathrm{LD}_{\mathrm{mlp}}\right)$ and from the absolute lateral position $\left(\mathrm{LD}_{\text {alp }}\right)$ for $8 \mathrm{~s}$ as previously suggested (Verster et al., 2014; Verster et al., 2018) (Fig. 1). The former essentially defines a lane drift as the event where a driver crosses the lane border for more than $8 \mathrm{~s}$, whereas the latter qualifies a lane drift as any lateral displacement $>100 \mathrm{~cm}$ that occurs within a time window of $8 \mathrm{~s}$. The automated algorithm was programmed to calculate mean SDLP and to count the number of lane drift according to the two definitions given above.

\section{Statistical analysis}

For the statistical analysis, participant data was grouped per treatment. First, in order to assure that the method of calculating the SDLP, i.e., as the standard deviation of the entire test as opposed to the average of the standard deviations per $5-\mathrm{km}$ segment, did not affect the relative drug effects reported in the original investigations, the Pearson correlation was determined between the two calculation methods for the largest group in the sample, i.e., participants treated with zopiclone $7.5 \mathrm{mg}$ and placebo $(N=194)$, but not for all available test drives since the aggregation and parallel analysis of all datasets is time costly and was not considered necessary to make this minor point. Next, in order to investigate whether lane drifts are indeed sensitive measures for observing driving impairment, the statistical significance of the difference in SDLP values between each treatment and the respective baseline condition was tested with a paired samples t-test. For the statistical testing of the difference in number of $\mathrm{LD}_{\mathrm{mlp}}$ and $\mathrm{LD}_{\mathrm{alp}}$ between the treatment and baseline conditions, the non-parametric Wilcoxon signed rank test was selected because of the severe skewedness of the data which could not be resolved by logarithmic transformations. In addition, the correlation between the SDLP and number of $\mathrm{LD}_{\text {alp }}$ in the treatment conditions, and the correlation between the increase in SDLP ( $\triangle$ SDLP) and the number of lane drifts was determined. It was hypothesized that if lane drifts are a true measure of driving impairment rather than a mere transformation of the SDLP, the relationship between the number of LD and the $\triangle$ SDLP should be stronger and more consistent than the relationship between the LD and the absolute SDLP values during treatment, considering that it is the increase in SDLP which conveys information about driving impairment rather than the absolute SDLP value. If the correlation between the lane drifts and absolute SDLP values are stronger, this suggests that lane drifts are a mere transformation of SDLP rather than a measure of driving impairment. Because the scatterplots suggested a quadratic pattern for both relationships, Spearman's $\rho\left(\mathrm{r}_{\mathrm{s}}\right)$ was chosen over Pearson's $r$. Lastly, in order to further investigate the independence of lane drifts from the SDLP, the Spearman correlation was calculated between the baseline values of the SDLP of individuals and their $\triangle$ SDLP during treatments, as well as the correlation between the baseline SDLP values of individuals and their $\Delta \mathrm{LD}_{\mathrm{alp}}$ during treatment. It is to be expected that neither the $\triangle$ SDLP nor the $\Delta \mathrm{LD}_{\text {alp }}$ correlates significantly with the baseline SDLP since the variation in the baseline SDLP is not assumed to reflect driving performance or driver fitness. For all statistical tests, the significance level was set at $\alpha=0.05$. All statistical analyses were conducted using the statistical package for the social sciences (SPSS) edition 24 offered by IBM.

\section{Results}

The Pearson correlation between SDLP values calculated from the mean lateral position over the entire ride and across segments was highly significant for the 194 zopiclone $7.5 \mathrm{mg}$ drives $(r[163]=0.84, p<0.001)$, as well as for the 194 
Table 1 Summary of included data. The time of the start of the driving test (tstart driving test) is relative to the time of drug administration

\begin{tabular}{|c|c|c|c|}
\hline Study & Treatment & tstart driving test & Research center \\
\hline Kuypers et al. (2008) & $\begin{array}{l}\text { Alcohol } 0.5 \mathrm{~g} / \mathrm{L}(N=18) \\
\text { Placebo }(N=18)\end{array}$ & $\begin{array}{l}+2 \mathrm{~h} \\
+2 \mathrm{~h}\end{array}$ & Maastricht University \\
\hline van der Sluiszen et al. (2016) & $\begin{array}{l}\text { Alcohol } 0.5 \mathrm{~g} / \mathrm{L}(N=31) \\
\text { Placebo }(N=31)\end{array}$ & $\begin{array}{l}+1.5 \mathrm{~h} \\
+1.5 \mathrm{~h}\end{array}$ & Maastricht University \\
\hline Vermeeren et al. (2014) & $\begin{array}{l}\text { Zopiclone } 7.5 \mathrm{mg}(N=40) \\
\text { Placebo }(N=40)\end{array}$ & $\begin{array}{l}+9 \mathrm{~h} \\
+9 \mathrm{~h}\end{array}$ & Maastricht University \\
\hline Vermeeren et al. (2015) & $\begin{array}{l}\text { Zopiclone } 7,5 \mathrm{mg}(N=28) \\
\text { Placebo }(N=28)\end{array}$ & $\begin{array}{l}+9 h \\
+9 h\end{array}$ & Maastricht University \\
\hline Vermeeren et al. (2016) & $\begin{array}{l}\text { Zopiclone } 7.5 \mathrm{mg}(N=24) \\
\text { Placebo }(N=24)\end{array}$ & $\begin{array}{l}+9 \mathrm{~h} \\
+9 \mathrm{~h}\end{array}$ & Maastricht University \\
\hline Vermeeren et al. (2018) & $\begin{array}{l}\text { Zopiclone } 7.5 \mathrm{mg}(N=48) \\
\text { Placebo }(N=48)\end{array}$ & $\begin{array}{l}+9 \mathrm{~h} \\
+9 \mathrm{~h}\end{array}$ & Maastricht University \\
\hline Mets et al. (2011) & $\begin{array}{l}\text { Zopiclone } 7.5 \mathrm{mg}(N=29) \\
\text { Placebo }(N=29)\end{array}$ & $\begin{array}{l}+8.5 \mathrm{~h} / 10 \mathrm{~h} \\
+8.5 \mathrm{~h} / 10 \mathrm{~h}\end{array}$ & Utrecht University \\
\hline Leufkens et al. (2009) & $\begin{array}{l}\text { Zopiclone } 7.5 \mathrm{mg}(N=25) \\
\text { Zolpidem } 10 \mathrm{mg}(N=24) \\
\text { Placebo }(N=25)\end{array}$ & $\begin{array}{l}+10 \mathrm{~h} \\
+5 \mathrm{~h} \\
+5 \mathrm{~h} /+10 \mathrm{~h}\end{array}$ & Maastricht University \\
\hline Verster et al. (2002) & $\begin{array}{l}\text { Zolpidem } 10 \mathrm{mg}(N=23) \\
\text { Zolpidem } 20 \mathrm{mg}(N=25) \\
\text { Placebo }(N=27)\end{array}$ & $\begin{array}{l}+4 \mathrm{~h} \\
+4 \mathrm{~h} \\
+4 \mathrm{~h}\end{array}$ & Utrecht University \\
\hline Jongen et al. (2018) & $\begin{array}{l}\text { Diazepam } 10 \mathrm{mg}(N=21) \\
\text { Oxazepam } 30 \mathrm{mg}(N=22) \\
\text { Oxazepam } 10 \mathrm{mg}(N=21) \\
\text { Placebo }(N=22)\end{array}$ & $\begin{array}{l}+4 \mathrm{~h} \\
+4 \mathrm{~h} \\
+4 \mathrm{~h} \\
+4 \mathrm{~h}\end{array}$ & Maastricht University \\
\hline Jongen et al. (2015) & $\begin{array}{l}\text { Sleep deprivation }(N=23) \\
\text { Normal sleep }(N=23)\end{array}$ & - & Maastricht University \\
\hline
\end{tabular}

corresponding baseline drives $(r[163]=0.89, p<0.001)$. For all treatment conditions, a significant increase in SDLP was observed compared to baseline. Overall, only $14 \mathrm{LD}_{\mathrm{mlp}}$ events were detected during treatment conditions, and only $3 \mathrm{LD}_{\mathrm{mlp}}$ events occurred during baseline. $\mathrm{LD}_{\mathrm{mlp}}$ did not significantly differ between treatments and baseline. $\mathrm{LD}_{\text {alp }}$ events however occurred very frequently. A total of $1646 \mathrm{LD}_{\text {alp }}$ events were established in the treatment conditions vs. 470 events during the baseline conditions. As can be seen in Fig. 2, the distribution was positively skewed, with the majority of test drives in the treatment conditions $(54.5 \%)$ including no or a single $\mathrm{LD}_{\mathrm{alp}}$ event. About $7.5 \%$ of the sample accounted for approximately $50 \%$ of all detected $\mathrm{LD}_{\text {alp }}$. Overall, the number of $\mathrm{LD}_{\text {alp }}$ was significantly higher during most treatments as compared to baseline, with the exception of the oxazepam $10 \mathrm{mg}$ and diazepam $10 \mathrm{mg}$ conditions.

The correlation analyses demonstrated a consistent and highly significant correlation between SDLP and the number of $\mathrm{LD}_{\text {alp }}$ after treatment $(r s(400)=0.77, p<0.001)$. Also, the correlation between the $\triangle \mathrm{SDLP}$ and the number of $\mathrm{LD}_{\mathrm{alp}}$ during the treatment conditions was significant $(r s(400)=$ $0.50, p<0.001)$. Significant correlations between SDLP and number of LDalp and $\triangle$ SDLP and LDalp across treatment conditions are shown in Fig. 3.
For each treatment separately, correlations between SDLP and number of $\mathrm{LD}_{\mathrm{alp}}$ in the treatment conditions were found to be significant as well as the correlation between the $\triangle$ SDLP and $\mathrm{LD}_{\mathrm{alp}}$ with the exception of the alcohol condition. The correlation analysis of the relationship between the baseline SDLP values on the one hand and $\triangle \mathrm{SDLP}$ and $\Delta \mathrm{LD}_{\text {alp }}$ on the other only yielded a significant Spearman correlation between the baseline SDLP and the $\Delta \mathrm{LD}_{\text {alp }}$ in the zopiclone $7.5 \mathrm{mg}$ group $(r s(192)=0.20, p=0.004)$, but no significant correlation between the baseline SDLP values and the $\triangle$ SDLP in this same treatment group $(r s(192)=-0.11, p=0.14)$. All other correlations were found to be insignificant. Table 2 provides a summary of the results.

\section{Discussion}

The primary goal of the current investigation was to validate lane drifts as an outcome measure of drug- and sleepinessinduced driver impairment as proposed by Verster et al. (Verster et al., 2014; Verster et al., 2018). An automated algorithm determined the number of lane drifts relative to the mean lateral position with a duration of at least $8 \mathrm{~s}\left(\mathrm{LD}_{\mathrm{mlp}}\right)$ and the number of lane drifts relative to the absolute lateral position 
Fig. 1 Illustrations depicting a lane drift relative to the mean lateral position (LDmlp) and lane drifts relative to the absolute lateral position (LDalp)
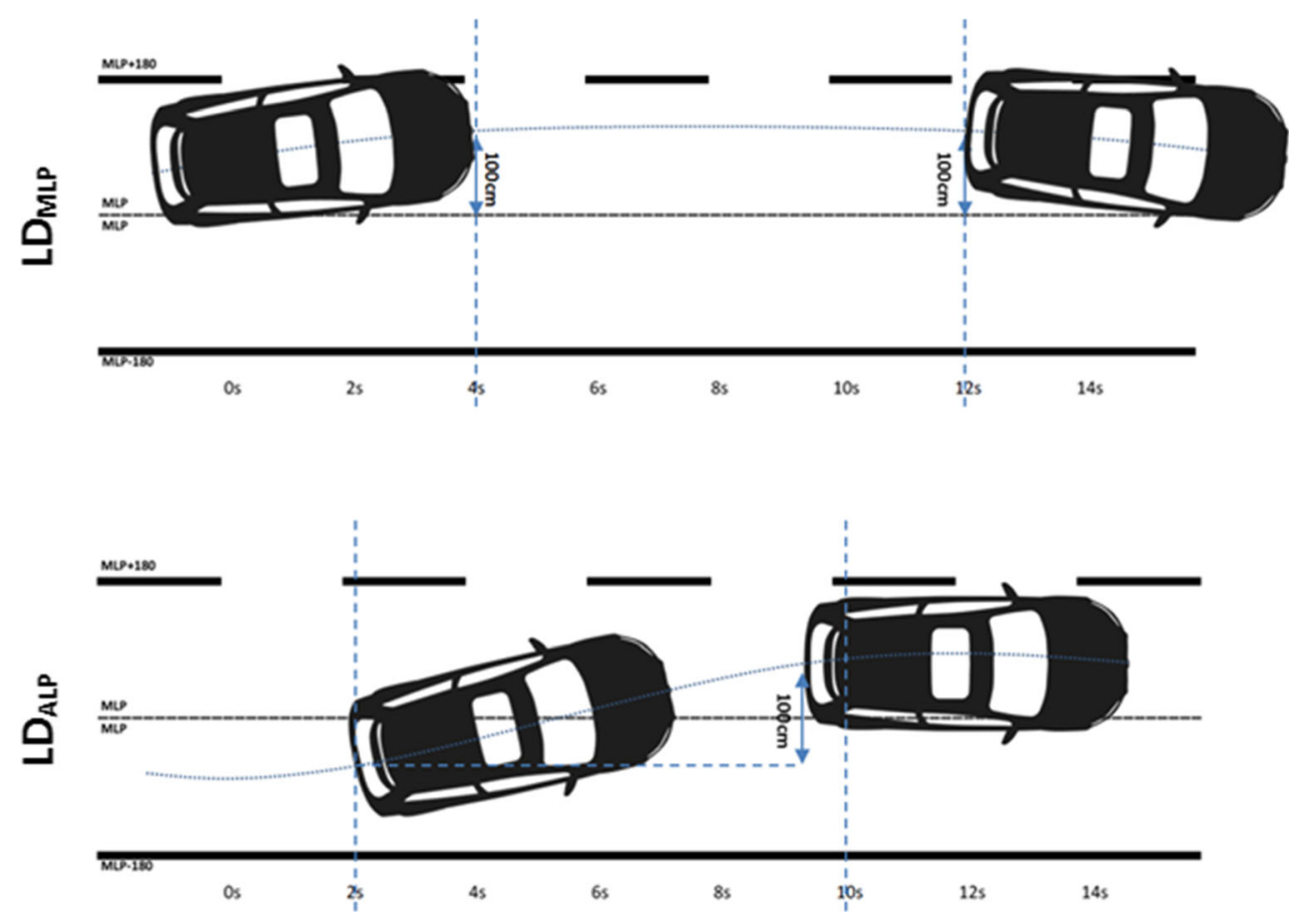

within a time window of $8 \mathrm{~s}\left(\mathrm{LD}_{\mathrm{alp}}\right)$ in a large data pool. This data pool contained data of 315 test drives after placebo administration or no treatment and 402 test drives after administration of a sedative substance or sleep deprivation. Over all 717 test drives, only $19 \mathrm{LD}_{\mathrm{mlp}}$ were detected. The number of $\mathrm{LD}_{\mathrm{mlp}}$ was not found to be significantly more prevalent in the treatment conditions. A total of $2116 \mathrm{LD}_{\text {alp }}$ were identified in all test drives. It was also found that the number of $\mathrm{LD}_{\text {alp }}$ was significantly higher in the treatment conditions with the exception of the oxazepam $10 \mathrm{mg}$ and diazepam $10 \mathrm{mg}$ conditions.

It appears that $\mathrm{LD}_{\mathrm{mlp}}$ are rare events. As a result, the outcome measure is unable to significantly discriminate between any treatment and respective baseline condition, despite the evident increase of the SDLP after all treatments. It is therefore clear that $\Delta \mathrm{LD}_{\mathrm{mlp}}$ as an outcome measure has an inferior sensitivity, if any, to driving impairment compared to the $\triangle$ SDLP. In contrast to $\mathrm{LD}_{\mathrm{mlp}}$, multiple $\mathrm{LD}_{\text {alp }}$ were detected in every condition. The events appeared relatively frequently. However, the majority of drivers exhibited no or only one $\mathrm{LD}_{\text {alp }}$ during treatment. The distribution of $\mathrm{LD}_{\text {alp }}$ was highly skewed with less than $10 \%$ of the participants accounting for approximately half of all detected events. The number of $\mathrm{LD}_{\text {alp }}$ was nearly always significantly higher in the treatment than in the baseline conditions, with the exception of the
Fig. 2 Histogram of the number of lane drifts relative to the absolute lateral position (LDalp) during the treatment conditions $(N=402)$

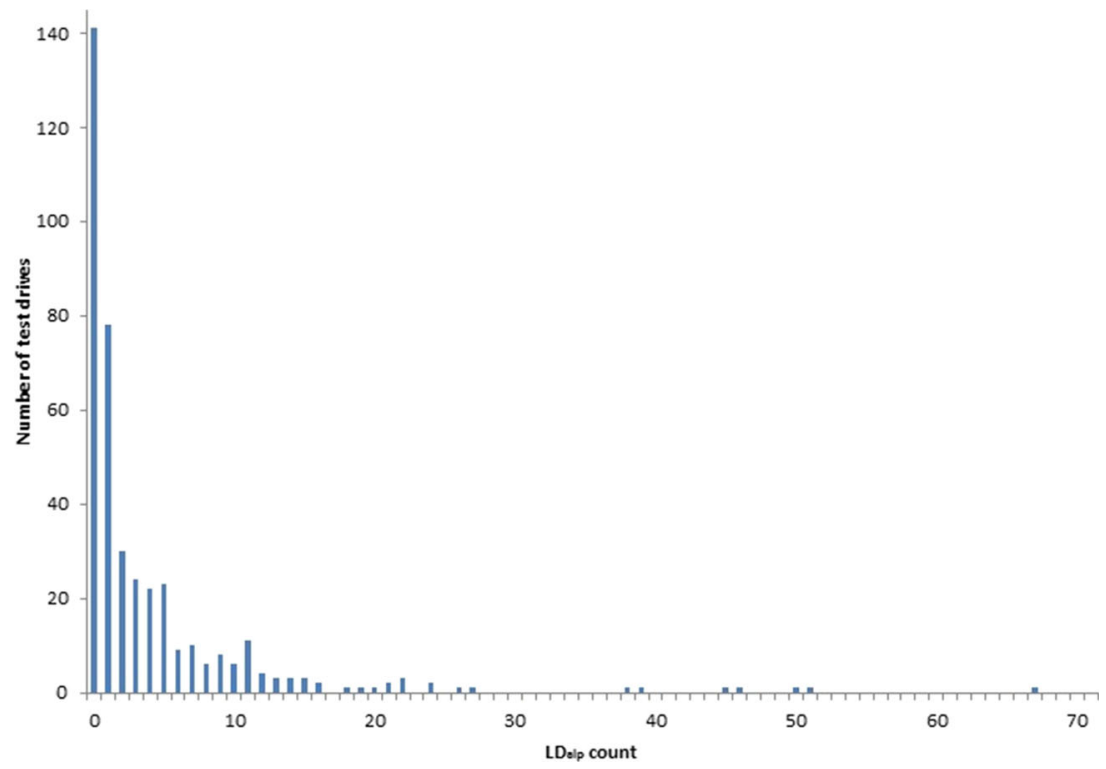


Fig. 3 Scatterplots depicting the relationships between $[\mathbf{A}]$ the SDLP values and the number of lane drifts relative to the absolute lateral position(LDalp), and [B] the change in SDLP between placebo and treatment and the number of LDalp
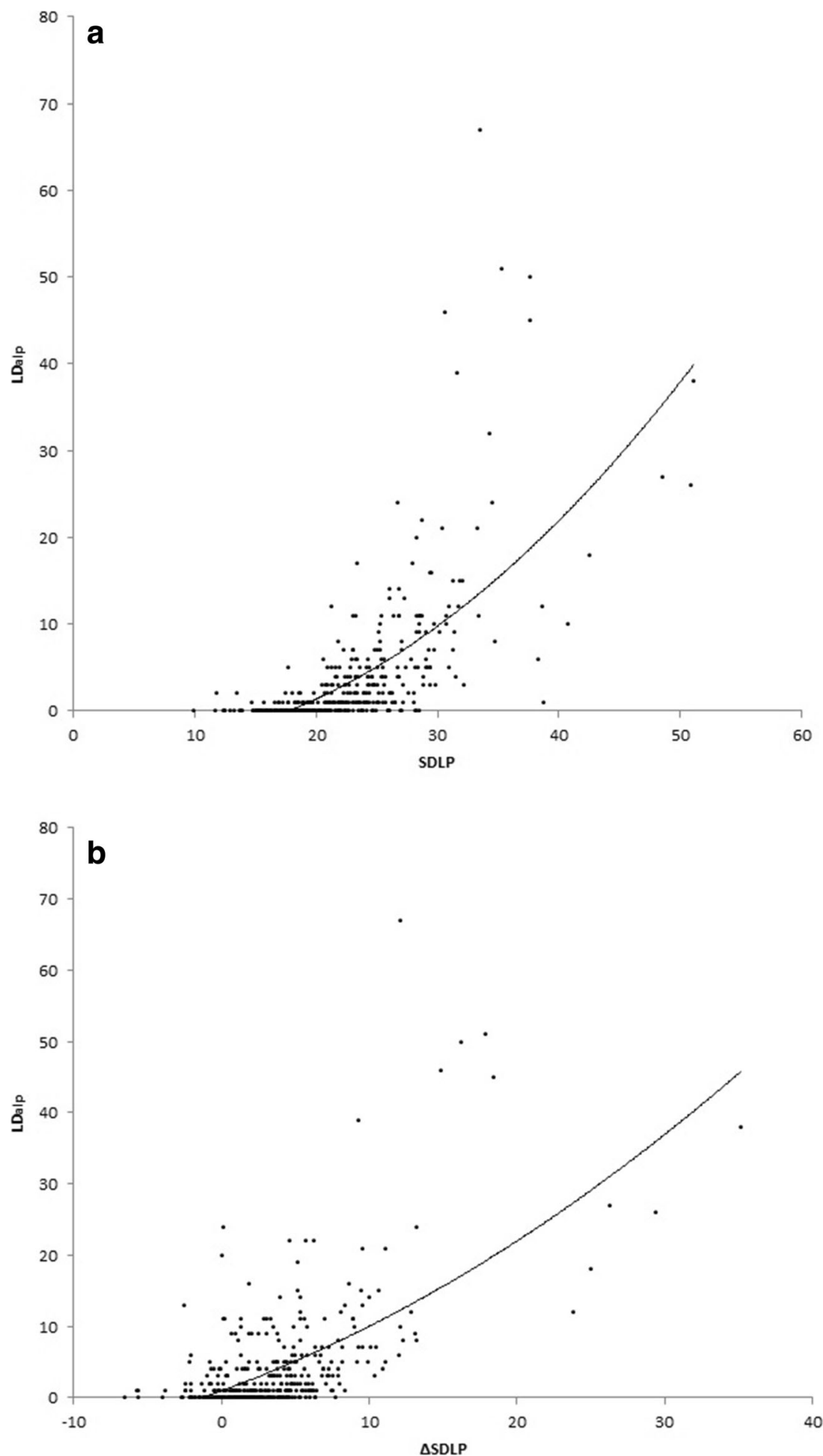

oxazepam $10 \mathrm{mg}$ and diazepam $10 \mathrm{mg}$ conditions. The absence of an effect could be attributed to the fact that in these conditions two drives were prematurely terminated, resulting in less opportunity for lane drifts to occur. In contrast, the increase in SDLP was found to be significant in all treatment conditions which suggest that the $\triangle$ SDLP is more sensitive for the detection of driving impairment, even if the duration of the test is shortened. An inspection of the correlation coefficients in Table 2 demonstrates that there is a close positive relationship between the number of SDLP and the $\mathrm{LD}_{\mathrm{alp}}$ in the treatment conditions, as well as between the $\triangle$ SDLP and the $\mathrm{LD}_{\mathrm{alp}}$. The former relationship was overall found to be 


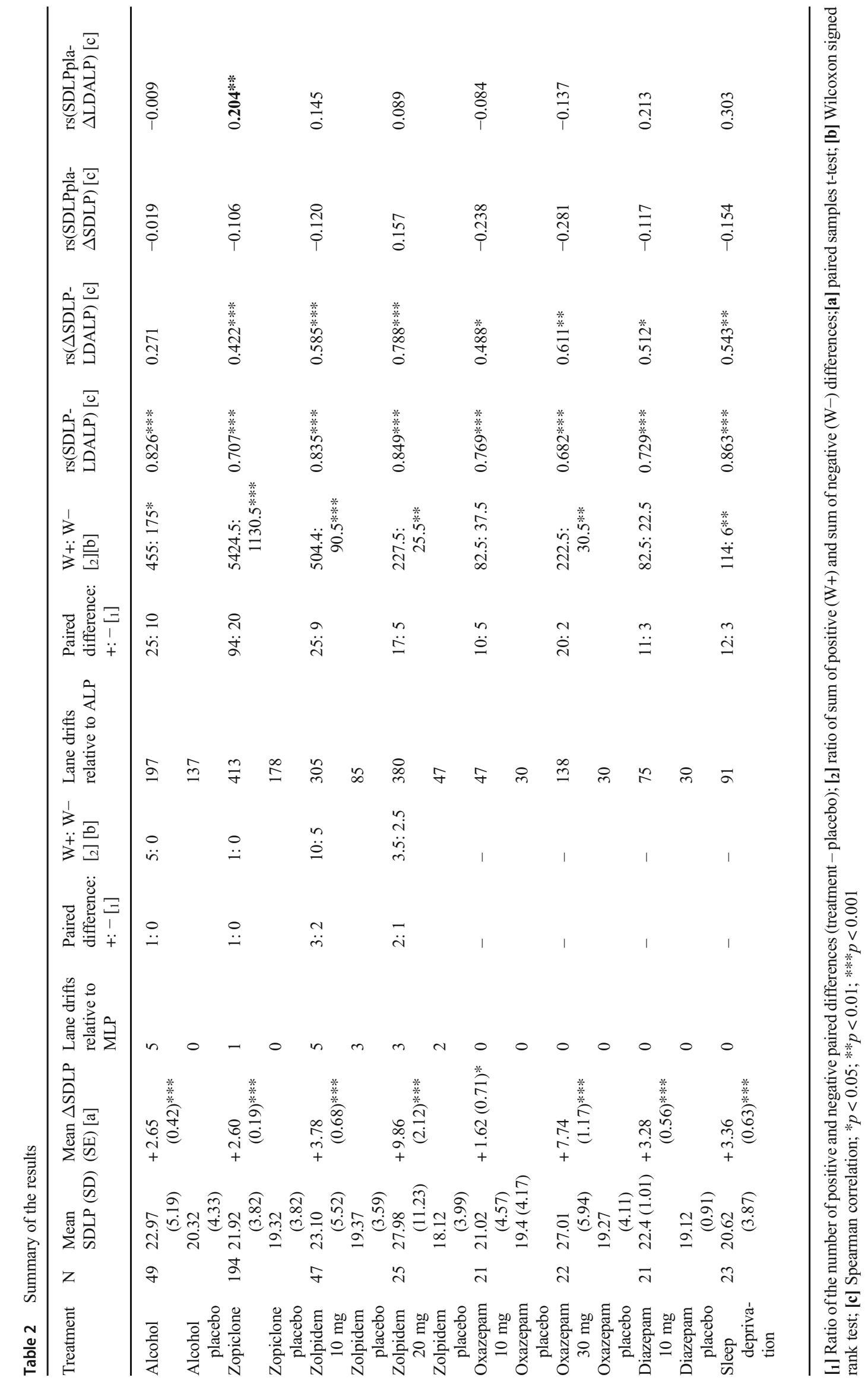


stronger and more consistent across different treatments. The close relationship between the outcome measures is not surprising given that they are both derived from the lateral position of the vehicle.

As mentioned, the relationship between the absolute SDLP and $\mathrm{LD}_{\text {alp }}$ was overall stronger than the relationship between the $\triangle \mathrm{SDLP}$ and $\mathrm{LD}_{\mathrm{alp}}$. However, if $\mathrm{LD}_{\text {alp }}$ is a true measure of driving impairment, it would be expected that a closer relationship should exist between the $\triangle$ SDLP and $L_{\text {alp }}$. The absolute SDLP value is known to differ considerably between healthy individuals treated with placebo, while the test-retest reliability of the SDLP has been found to be high (Verster \& Roth, 2011). Hence, the SDLP can be considered as a driving characteristic that varies considerably between healthy individuals, but not within, and therefore conveys little information about driving impairment per se. For this reason, it is the increase in SDLP $(\triangle \mathrm{SDLP})$ relative to placebo or baseline performance that is used in on-the-road driving studies to assess driving impairment. The close relationship between the absolute SDLP and $\mathrm{LD}_{\text {alp, }}$ while the relationship between the $\triangle$ SDLP and the $\mathrm{LD}_{\text {alp }}$ was found to be less strong and less consistent, suggests that $\mathrm{LD}_{\mathrm{alp}}$ is simply a transformation of the SDLP rather than an independent measure of driving impairment. The absence of a correlation between baseline SDLP and treatment-induced $\triangle$ SDLP and the presence of a significant correlation between baseline SDLP and a treatment (zopiclone)-induced $\Delta \mathrm{LD}_{\text {alp }}$ support this notion. It demonstrates that the $\triangle \mathrm{SDLP}$ is independent from the baseline SDLP, while detection of $\mathrm{LD}_{\text {alp }}$ is biased toward participants with higher baseline SDLP values. However, for $\mathrm{LD}_{\mathrm{alp}}$ to be a true measure of driving impairment, the increase in $\mathrm{LD}_{\mathrm{alp}}$ should occur independent from the baseline SDLP value. The observation that this is not the case is problematic.

Consideration of the statistical nature of the SDLP can explain why the relationship between the absolute SDLP and the $\mathrm{LD}_{\text {alp }}$ count is stronger than the relation between the $\triangle \mathrm{SDLP}$ and $\Delta \mathrm{LD}_{\mathrm{alp}}$, as well as provide an explanation for the modest correlation between the baseline SDLP and the increase in

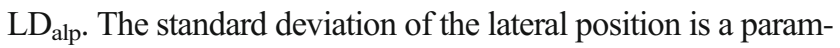
eter of the width of the confidence interval of the lateral position. It can be calculated that the $99 \%$ confidence interval of the lateral position is about $100-\mathrm{cm}$ wide when a participant drives with a mean SDLP of $19.45 \mathrm{~cm}$. As a result, participants with a SDLP under $19.45 \mathrm{~cm}$ would likely exhibit no $\mathrm{LD}_{\text {alp }}$, i.e., never produce a lane drift that spans more than $100 \mathrm{~cm}$, despite the possibility of experiencing significant road tracking impairment as indicated by the SDLP. Therefore, the relationship between the absolute SDLP and $\mathrm{LD}_{\text {alp }}$ count is stronger than the relation between $\triangle$ SDLP and $\mathrm{LD}_{\text {alp }}$. This also means that participants with a low baseline SDLP of, e.g., $16 \mathrm{~cm}$, should show greater impairment in road tracking ability as quantified by the $\triangle$ SDLP during the treatment condition than a participant with a high baseline SDLP of, e.g., $19 \mathrm{~cm}$, in order to exceed the threshold of $19.45 \mathrm{~cm}$. Taken together, the high correlation between the absolute SDLP and absolute $\mathrm{LD}_{\text {alp }}$ count and the statistical bias toward participants with higher inherent SDLP values suggest that $\mathrm{LD}_{\text {alp }}$ is a linear transformation of the SDLP that conceivably adds no new information and is less sensitive to impairment than the $\triangle$ SDLP.

Besides the abovementioned problems with the $\mathrm{LD}_{\mathrm{mlp}}$ and $\mathrm{LD}_{\text {alp }}$ as parameters of driving impairment, a more fundamental issue remains. Verster et al. (Verster et al., 2014; Verster et al., 2018; Verster \& Roth, 2014a) proposed lane drifts as a measure of momentary lapses of attention which were defined as "short periods of inattention during which the driver experiences reduced alertness and does not focus on the task, or actually stops performing the task, resulting in driving impairment". However, it is uncertain whether a momentary lapse of attention leads to a significant change in lateral position. Of course, it appears likely that a significant lateral displacement would occur if the participant stops performing the task altogether. However, an event like this can arguably not be conceived as a lapse of attention, rather than falling asleep or losing consciousness. A lapse of attention is usually conceptualized as moment during which internal task irrelevant information is being processed at the cost of the processing of incoming external information and is often referred to as task unrelated thought (TUT) or mind wandering (Smallwood et al., 2004). A frequently employed lab task for the assessment of attentional lapses in this sense is the sustained attention to response task (SART). During this task, participants are instructed to respond to stimuli which are presented at a rapid pace and to withhold their response whenever a relatively infrequently presented target stimulus appears. A lapse is defined as a commission error, i.e., responding to the target stimulus which requires inhibition of a response. It has been argued that commission errors during the SART are the result of poor top-down motor control (motor decoupling), rather than inattention to external stimuli (perceptual decoupling) (Head \& Helton, 2013), or both (Seli, 2016). Whatever the case, it is clear that higher level functioning can be impaired while lower level functioning, i.e., indiscriminant and automated responding to any stimulus, remains intact. Arguably, for experienced drivers, road tracking is also a highly automated skill which requires little focused attention. It is therefore reasonable to assume that a short period of inattention does not necessarily result in a measurable change in lateral position. Future research should adopt established physiological and behavioral measures of attention in order to assess if and when drivers experience attentional lapses and whether this is reflected in the lateral position of the vehicle.

\section{Conclusion}

Lane drifts relative to the mean lateral position $(\geq 100 \mathrm{~cm})$ which last for at least $8 \mathrm{~s}$ are not a useful outcome measure 
of drug- and sleepiness-induced driving impairment. Due to the rare occurrence, it is unable to demonstrate driving impairment in various treatment conditions despite SDLP showing significant treatment-induced increases. Lane drifts relative to the absolute lateral position $(\geq 100 \mathrm{~cm})$ which occur within a window of $8 \mathrm{~s}$ did occur frequently and were able to demonstrate treatment-induced driving impairment in most conditions. However, the measure seems to be a simple transformation of the SDLP with inferior sensitivity to treatment-induced driver impairment. Also, the detection rate is biased in the direction of drivers with higher inherent SDLP values. It is therefore concluded that this outcome has little or no additional value to the SDLP as an outcome measure of the on-theroad driving test.

Funding information Joris Verster has received grants/research support from the Dutch Ministry of Infrastructure and the Environment, Janssen, Nutricia, Red Bull, Sequential, and Takeda and has acted as a consultant for the Canadian Beverage Association, Centraal Bureau Drogisterijbedrijven, Clinilabs, Coleman Frost, Danone, Deenox, Eisai, Janssen, Jazz, More Labs, Purdue, Red Bull, Sanofi-Aventis, Sen-Jam Pharmaceutical, Sepracor, Takeda, Toast!, Transcept, Trimbos Institute, Vital Beverages, and ZBiotics.

Open Access This article is licensed under a Creative Commons Attribution 4.0 International License, which permits use, sharing, adaptation, distribution and reproduction in any medium or format, as long as you give appropriate credit to the original author(s) and the source, provide a link to the Creative Commons licence, and indicate if changes were made. The images or other third party material in this article are included in the article's Creative Commons licence, unless indicated otherwise in a credit line to the material. If material is not included in the article's Creative Commons licence and your intended use is not permitted by statutory regulation or exceeds the permitted use, you will need to obtain permission directly from the copyright holder. To view a copy of this licence, visit http://creativecommons.org/licenses/by/4.0/.

\section{References}

Maycock G (1996) Sleepiness and driving: the experience of UK car drivers. J Sleep Res 5(4):229-231

Jongen S, Vuurman E, Ramaekers J, Vermeeren A (2018) Comparing the effects of oxazepam and diazepam in actual highway driving and neurocognitive test performance: a validation study. Psychopharmacology. 235(4):1283-1294

Barbone F, McMahon A, Davey P, Morris A, Reid I, McDevitt D, MacDonald T (1998) Association of road-traffic accidents with benzodiazepine use. Lancet 352(9137):1331-1336

Movig KL, Mathijssen M, Nagel P, Van Egmond T, De Gier JJ, Leufkens $\mathrm{H}$ et al (2004) Psychoactive substance use and the risk of motor vehicle accidents. Accid Anal Prev 36(4):631-636

Gustavsen I, Bramness JG, Skurtveit S, Engeland A, Neutel I, Mørland J (2008) Road traffic accident risk related to prescriptions of the hypnotics zopiclone, zolpidem, flunitrazepam and nitrazepam. Sleep Med 9(8):818-822

Orriols L, Philip P, Moore N, Castot A, Gadegbeku B, Delorme B et al (2011) Benzodiazepine-like hypnotics and the associated risk of road traffic accidents. Clinical Pharmacology \& Therapeutics 89(4):595-601
Ramaekers J (2017) Drugs and driving research in medicinal drug development. Trends Pharmacol Sci 38(4):319-321

Borkenstein RF, Crowther RF, Shumate R (1974) The role of the drinking driver in traffic accidents (The Grand Rapids Study). Blutalkohol 11(Suppl):1-131

Veldhuijzen DS, van Wijck AJ, Verster JC, Kenemans JL, Kalkman CJ, Olivier B, Volkerts ER (2006) Acute and subchronic effects of amitriptyline $25 \mathrm{mg}$ on actual driving in chronic neuropathic pain patients. J Psychopharmacol 20(6):782-788

Ramaekers J, Muntjewerff N, Van Veggel L, Uiterwijk M, O'Hanlon J (1998) Effects of nocturnal doses of mirtazapine and mianserin on sleep and on daytime psychomotor and driving performance in young, healthy volunteers. Hum Psychopharmacol Clin Exp 13(S2):S87-S97

Jongen S, Perrier J, Vuurman EF, Ramaekers JG, Vermeeren A (2015) Sensitivity and validity of psychometric tests for assessing driving impairment: effects of sleep deprivation. PLoS One 10(2): e0e117045

Lococo KH, Staplin L Literature review of polypharmacy and older drivers: identifying strategies to study drug usage and driving functioning among older drivers. 2006

Hartman RL, Brown TL, Milavetz G, Spurgin A, Pierce RS, Gorelick DA, Gaffney G, Huestis MA (2015) Cannabis effects on driving lateral control with and without alcohol. Drug Alcohol Depend 154:25-37

Verster JC, Bervoets AC, de Klerk S, Roth T (2014) Lapses of attention as outcome measure of the on-the-road driving test. Psychopharmacology. 231(1):283-292

Verster JC, Mooren L, Bervoets AC, Roth T (2018) Highway driving safety the day after using sleep medication: the direction of lapses and excursions out-of-lane in drowsy drivers. J Sleep Res 27(3): e12622

Verster JC, Roth T (2014a) Excursions out-of-lane versus standard deviation of lateral position as outcome measure of the on-the-road driving test. Hum Psychopharmacol Clin Exp 29(4):322-329

Mets MA, De Vries JM, de Senerpont Domis LM, Volkerts ER, Olivier B, Verster JC (2011) Next-day effects of ramelteon $(8 \mathrm{mg})$, zopiclone $(7.5 \mathrm{mg})$, and placebo on highway driving performance, memory functioning, psychomotor performance, and mood in healthy adult subjects. Sleep. 34(10):1327-1334

Verster JC, Roth T (2014b) Methylphenidate significantly reduces lapses of attention during on-road highway driving in patients with ADHD. J Clin Psychopharmacol 34(5):633-636

Kuypers KP, Samyn N, Ramaekers JG (2006) MDMA and alcohol effects, combined and alone, on objective and subjective measures of actual driving performance and psychomotor function. Psychopharmacology. 187(4):467-475

van der Sluiszen N, Vermeeren A, Jongen S, Theunissen E, van Oers A, Van Leeuwen $C$ et al (2016) On-the-road driving performance after use of the antihistamines mequitazine and l-mequitazine, alone and with alcohol. Psychopharmacology. 233(18):3461-3469

Leufkens TR, Lund JS, Vermeeren A (2009) Highway driving performance and cognitive functioning the morning after bedtime and middle-of-the-night use of gaboxadol, zopiclone and zolpidem. J Sleep Res 18(4):387-396

Vermeeren A, Jongen S, Murphy P, Moline M, Filippov G, Pinneer K et al (2018) On-the-road driving performance the morning after bedtime administration of lemborexant in healthy adult and elderly volunteers. Sleep

Vermeeren A, Vets E, Vuurman EF, Van Oers AC, Jongen S, Laethem T et al (2016) On-the-road driving performance the morning after bedtime use of suvorexant 15 and $30 \mathrm{mg}$ in healthy elderly. Psychopharmacology. 233(18):3341-3351

Vermeeren A, Sun H, Vuurman EF, Jongen S, Van Leeuwen CJ, Van Oers $\mathrm{AC}$ et al (2015) On-the-road driving performance the morning after 
bedtime use of suvorexant 20 and $40 \mathrm{mg}$ : a study in non-elderly healthy volunteers. Sleep. 38(11):1803-1813

Vermeeren A, Vuurman EF, Leufkens TR, Van Leeuwen CJ, Van Oers AC, Laska E et al (2014) Residual effects of low-dose sublingual zolpidem on highway driving performance the morning after middle-of-the-night use. Sleep. 37(3):489-496

Verster JC, Volkerts ER, Schreuder AH, Eijken EJ, van Heuckelum JH, Veldhuijzen DS, Verbaten MN, Paty I, Darwish M, Danjou P, Patat A (2002) Residual effects of middle-of-the-night administration of zaleplon and zolpidem on driving ability, memory functions, and psychomotor performance. J Clin Psychopharmacol 22(6):576-583

O'Hanlon J, Haak T, Blaauw G, Riemersma J (1982) Diazepam impairs lateral position control in highway driving. Science. 217(4554):7981

Ramaekers JG, Uiterwijk M, O'hanlon J (1992) Effects of loratadine and cetirizine on actual driving and psychometric test performance, and EEG during driving. Eur J Clin Pharmacol 42(4):363-369

O'Hanlon J (1984) Driving performance under the influence of drugs: rationale for, and application of, a new test. Br J Clin Pharmacol 18(S1):121S-129S
Verster JC, Roth T (2011) Standard operation procedures for conducting the on-the-road driving test, and measurement of the standard deviation of lateral position (SDLP). International journal of general medicine 4:359-371

Smallwood J, Davies JB, Heim D, Finnigan F, Sudberry M, O'Connor R, Obonsawin M (2004) Subjective experience and the attentional lapse: task engagement and disengagement during sustained attention. Conscious Cogn 13(4):657-690

Head J, Helton WS (2013) Perceptual decoupling or motor decoupling? Conscious Cogn 22(3):913-919

Seli P (2016) The attention-lapse and motor decoupling accounts of SART performance are not mutually exclusive. Conscious Cogn 41:189-198

Publisher's note Springer Nature remains neutral with regard to jurisdictional claims in published maps and institutional affiliations. 